\title{
Study of oxygen effect on the melting pool temperature during selective laser melting
}

\author{
M. Doubenskaia ${ }^{1,2}$, D. Kotoban ${ }^{1, a}$ And I. Zhirnov ${ }^{1,2}$ \\ 1 Moscow State University of Technology "STANKIN", Vadkovsky per. 1, Moscow 127994, Russia \\ ${ }^{2}$ University of Lyon, National Engineering School of Saint-Etienne, LTDS Laboratory, Saint-Etienne, France
}

Received 16 September 2016, Accepted 8 November 2016

\begin{abstract}
The on-line optical diagnostics studies of selective laser melting are difficult to accomplish due to the need of closed chamber of inert gas protective atmosphere. In this term, this study was initiated to make evidence of oxygen influence on the signal from the melt pool. The results make clear the temperature growth with presence of oxygen and its effect on the metallurgical contact of the single-track to the substrate. It was shown that for both used materials, the oxidation leads to an overheating but the metallographic quality differs. The experiments highlighted that the optical diagnostic means such as IR thermography camera is suitable but not sufficient solution for process control and it needs adequate evaluation. Using the track width as an approximation of the melt pool width at melting point, it was possible with some assumptions to restore the true temperature of the studied zone.
\end{abstract}

Key words: Thermography / optical diagnostic / IR-camera / selective laser melting / oxidation

\section{Introduction}

The temperature is one of the main parameters of material in the exposed zone in additive manufacturing technologies and more precisely in selective laser melting (SLM) [1]. Since the temperature has direct impact on the material structure and the properties of material are structure-depended it is evident that the temperature measuring has great potential in process control of laser technologies.

Controlling the working zone i.e. melt pool in SLM is difficult due to the limited space in protective atmosphere chamber [2]. The possible solution could be to integrate the diagnostic means in the laser optical track but it still hard to make due to the following reasons. First of all, there is need of optical elements capability for working with multiple wavelengths especially for galvanometer optics. The optical system of the SLM equipment should be expanded to mount the additional optical diagnostic tools as well as there is need in some free place inside the chamber. The second main problem concerns a need of calibration with the model of black body since the calibration should be carried out include optical system. The calibration allows translate the raw captured signal in brightness temperature i.e. the temperature of ideal black body corresponding to the input radiation inten-

${ }^{a}$ Corresponding author: d.kotoban@stankin.ru sity. In view of true temperature restoration, calibration is required step. That is why the most experimental data of melt pool thermal state in SLM was collected without using protective atmosphere [3-7]. Some works on optical diagnostic were conducted with usual and high-speed CCD camera coaxially with laser beam $[8,9]$ but without collecting data of the brightness or true temperatures.

There are a wide range of process parameters affected the process and melt pool properties that was established earlier $[10,11]$. In this works the especial need in high temporal and spatial resolution optical measurement equipment was highlighted to provide adequate studies since the working zone is characterized by high temperature gradients $\left(10^{5}-10^{7} \mathrm{~K} . \mathrm{m}^{-1}\right)$ and high cooling rates $\left(10^{5}\right.$ $\left.10^{6} \mathrm{~K} . \mathrm{s}^{-1}\right)$. In this case, typical thermal detectors are not suitable to the process control due to the low sensitivity and high dead time compared to the photoelectric detectors.

The capabilities of diagnostic means become wider if complex optical equipment is used $[1,3]$. It involves different methods to investigate the true temperature of working zone. Typical approach is to correlate the characteristic process phenomena with received raw signal.

In Reference [1] during the pulse periodic laser treatment, it was found the horizontal plateau of almost similar temperature where the solidification took place (1450 to $1600^{\circ} \mathrm{C}$ ). The lowest solidus temperature was accepted as the melting point so the brightness temperature could 
Table 1. Element composition of the 304L substrate.

\begin{tabular}{rccccccc}
\hline $\mathrm{Fe}$ & $\mathrm{C}$ & $\mathrm{Cr}$ & $\mathrm{Mn}$ & $\mathrm{Ni}$ & $\mathrm{P}$ & $\mathrm{S}$ & $\mathrm{Si}$ \\
\hline bal. & $<0.03$ & 19 & $<2.0$ & 12 & $<0.045$ & $<0.03$ & $<1.0$ \\
\hline
\end{tabular}

be translated to the true temperature using Planck law with assumption of the gray body model with calculated emissivity coefficient that was assumed constant for the wide range of the temperatures. In Reference [5] the authors were using a finite element analysis to predict the melting temperature and applied this isotherm on the IR-camera thermal imaging that allows finding a melt reference point and an emissivity coefficient. To restore the true temperature from brightness temperature, the single-track cross-section optical microscopy was applied in Reference [9]. The measurement allows to detect the geometry of the melt pool and to find the melting point. The analysis of process parameters variation on the pyrometer and IR-camera signal was carried out in Reference [6]. The authors showed the principal possibility to make an integrated control system for SLM process. As a conclusion, for the effective thermal analysis there are need to apply multi-wave pyrometer and IR-camera calibrated with the model of black body in wide temperature range. The appropriate method of emissivity coefficient and true temperature restoration should be evaluated.

Since the most previous studies were conducted in air atmosphere, this study was designated to find oxygen influence on the thermal behavior during SLM process for solid metallic surface and metal powders. It seems that oxidation has negative effect on the material properties in general but the process properties need to be investigated.

\section{Materials and methods}

For the preliminary study, the substrates of stainless steel AISI type 304L (the element composition is given in Tab. 1) were used with prepared surface of $R a 10 \mu \mathrm{m}$ and $3 \mu \mathrm{m}$. The study was performed in both air and argon atmosphere.

For the powder bed investigation two type of commercially available powders were used: AISI type 316L austenitic stainless steel and AISI type 410 martensitic stainless steel made by Sandvik Osprey Ltd. The nominal compositions are given in Table 2. Powders present almost spherical shape with less than $30 \mu \mathrm{m}$ of mean particles diameter.

The thermal properties of the materials are given in Table 3 (thermal conductivity by [12], other by standards). It is shown, that $304 \mathrm{~L}$ and $316 \mathrm{~L}$ have almost similar thermal properties instead of 410 steel that have greater thermal conductivity and melting point and lower specific heat capacity. In this regard, we had two materials in different state (solid 304L and powder 316L) with similar thermal properties and two powder materials with different thermal properties.
For the experiments, the laboratory-scale SLM machine was used. The applied laser was YLR-50 (IPG Photonics, Russia) continuous fiber laser with $50 \mathrm{~W}$ max. output power of the $\lambda=1.07 \mu \mathrm{m}$ wavelength. The optics provides $70 \mu \mathrm{m}$ of focused beam. Since there was need to make experimental work in specific conditions with protective atmosphere, the test bench of optical diagnostic was constructed that allows using of IR-camera FLIR Phoenix RDAÑ (FLIR Systems, Inc., USA) inside the protective atmosphere chamber (Fig. 1). The chamber was developed in such a way that the optical access was possible. The IR-camera was mounted with an angle of $45^{\circ}$ to the work surface.

The IR-camera has an InSb detector type working in the wavelength range 3 to $5 \mu \mathrm{m}$ of input signal. The view field of the camera was $3.52 \times 2.82 \mathrm{~mm}^{2}$ with $320 \times 56$ px rray of spatial resolution. The experiment was realized with exposure time of $9 \mu \mathrm{s}$ with measurement frequency up to $38 \mathrm{kHz}$. To provide brightness temperature measurements, the IR-camera was calibrated using the model of black body Micron M390 in the temperature range 900 to $3000{ }^{\circ} \mathrm{C}$.

The experiments on the solid substrates were conducted with and without protective atmosphere by realizing single-tracks and measurements. The protective atmosphere was provided with extra pure $99.9 \%$ argon with 2 l.min ${ }^{-1}$ gas flow. The second stage experiments were conducted with thin $(40 \mu \mathrm{m})$ and thick $(80 \mu \mathrm{m})$ layer of SS316L and $(40 \mu \mathrm{m})$ layer of SS410 powders with and without protective atmosphere by realizing singletracks and measurements. For each technological regime 3 single-tracks were made to collect a statistical data. The powders were sieved, blended and dried (at $120{ }^{\circ} \mathrm{C}$ for $\mathrm{h}$ each), and spreaded on the surface by automatic machine system that allows to precise control of powder thickness. Nevertheless, the thickness was controlled by optical microscopy measurement of the substrate and powder focus plane. The spreaded powder surface flatness was provided by automatic spreading system.

For the experiments without powder on the SS304L substrates $50 \mathrm{~W}$ of laser power and 50 to $300 \mathrm{~mm} . \mathrm{s}^{-1}$ of scanning speed were used. The IR-camera acquires the signal and since it was calibrated calculates the brightness temperature. By finding the reference point of solidliquid boundary and correlating it with the transversal temperature distribution, the emissivity coefficient could be determined. Since the solid-liquid boundary was considered at the track (remelted zone here) side border (we took the track width into account), there was possibility to take in consideration all the regimes with different track widths but almost similar brightness temperature. By assuming the gray body hypothesis where the emissivity coefficient is independent of the wavelength and temperature, the true temperature could be calculated by the Planck law (Eq. (1)). The assumption means that the better correlation of true temperature with real temperature is considered in the range of melting point (where the emissivity coefficient was caught) and the error grows with temperature moving up and down. The Equation (1) 
Table 2. Powders element composition.

\begin{tabular}{|c|c|c|c|c|c|c|c|c|}
\hline \multicolumn{9}{|c|}{ 316L powder } \\
\hline $\mathrm{Fe}$ & $\mathrm{C}$ & $\mathrm{Cr}$ & $\mathrm{Mn}$ & $\mathrm{Ni}$ & Mo & $\mathrm{P}$ & $\mathrm{S}$ & $\mathrm{Si}$ \\
\hline bal. & $<0.15$ & 17 & 2.0 & 12 & 2.5 & $<0.045$ & $<0.03$ & $<1.0$ \\
\hline \multicolumn{6}{|c|}{410 powder } & & & \\
\hline $\mathrm{Fe}$ & $\mathrm{C}$ & $\mathrm{Cr}$ & $\mathrm{Mn}$ & $\mathrm{P}$ & $\mathrm{S}$ & & & \\
\hline bal. & $<0.15$ & 12.5 & $<1.0$ & $<0.04$ & & & & \\
\hline
\end{tabular}

Table 3. Thermal properties of solid materials.

\begin{tabular}{cccc}
\hline Solid material & Melting point, ${ }^{\circ} \mathrm{C}$ & Thermal Conductivity, $\mathrm{W} / \mathrm{m} .{ }^{\circ} \mathrm{C}$ & Specific Heat Capacity, J/kg. ${ }^{\circ} \mathrm{C}$ \\
\hline 304L & $1400-1450$ & $14.76-33.53\left(20-1354{ }^{\circ} \mathrm{C}\right)$ & 500 \\
& & 28.99 at $152{ }^{\circ} \mathrm{C}($ liquid $)$ & 500 \\
$316 \mathrm{~L}$ & $1375-1400$ & $13.31-32.41\left(20-1371{ }^{\circ} \mathrm{C}\right)$ & \\
& & 27.24 at $142{ }^{\circ} \mathrm{C}$ (liquid) & 460 \\
410 & $1480-1530$ & $26.26-33.32\left(20-1482{ }^{\circ} \mathrm{C}\right)$ & \\
& & 30.81 at $1627^{\circ} \mathrm{C}$ (liquid) & \\
\hline
\end{tabular}

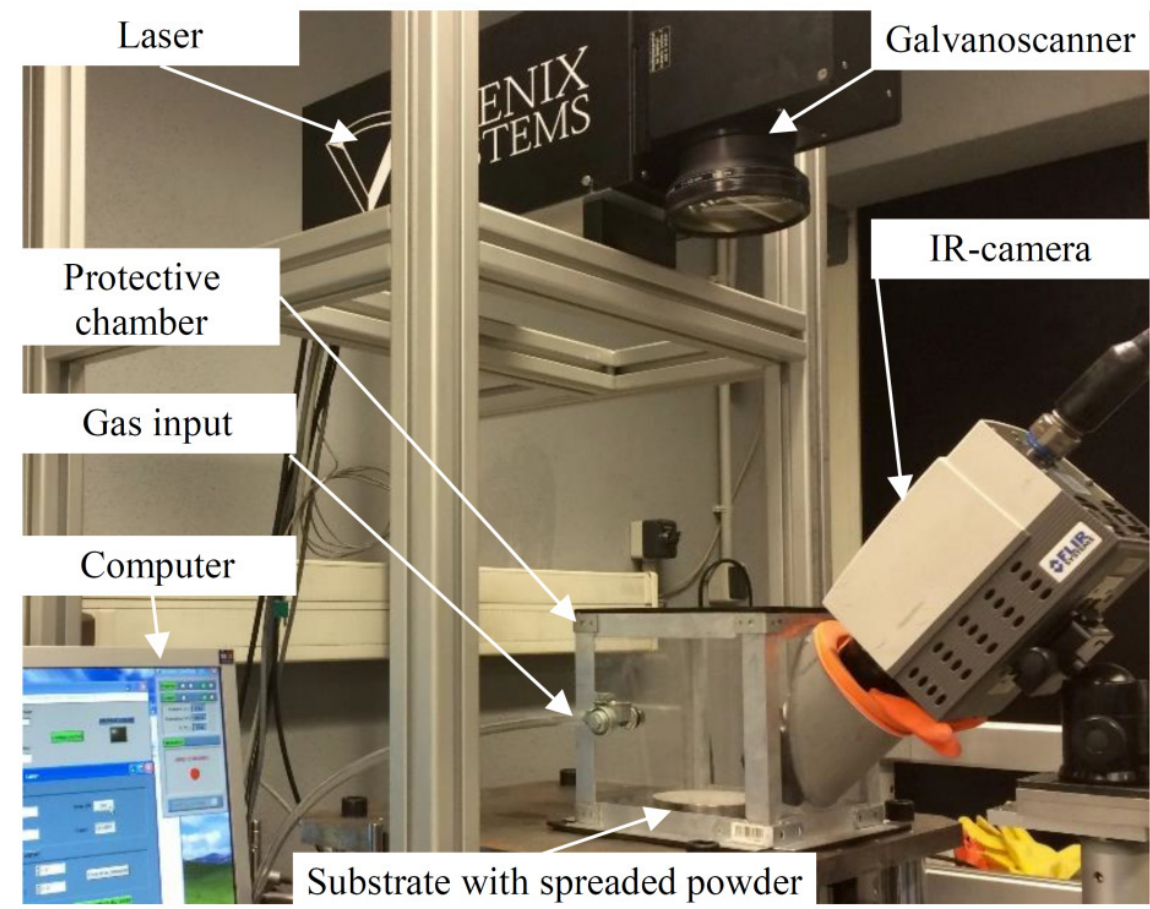

Fig. 1. Optical diagnostic test bench for SLM process.

was calculated numerically by substituting the input signal wavelengths of the IR-camera. For the melting point temperature the mean value between liquidus and solidus was taken.

$$
\int_{\lambda_{1}}^{\lambda_{2}}\left(\frac{2 h c^{2}}{\lambda^{5}} \frac{(\lambda)}{e^{\frac{h c}{\lambda k T_{T R}}}-1}\right) d \lambda=\int_{\lambda_{1}}^{\lambda_{2}}\left(\frac{2 h c^{2}}{\lambda^{5}} \frac{1}{e^{\frac{h c}{\lambda k T_{B R}}-1}}\right) d \lambda
$$

where: speed of light in vacuum $c=2,99792458 \times 108$ $\left[\mathrm{m} . \mathrm{s}^{-1}\right]$, Planck constant $h=6,626076 \times 10^{3} 4\left[\mathrm{~J} . \mathrm{s}^{-1}\right]$, Boltzmann constant $k=1,38 \times 10^{-23}\left[\mathrm{~J}_{\mathrm{K}}{ }^{-1}\right]$, true temperature $T_{\mathrm{TR}}[\mathrm{K}]$, brightness temperature $T_{\mathrm{BR}}[\mathrm{K}]$, emissivity coefficient $\varepsilon$ and input signal wavelength $\lambda[\mathrm{m}]$,
IR-camera wavelengths $\lambda_{1}=3 \times 10^{-6}[\mathrm{~m}]$ and $\lambda_{2}=$ $5 \times 10^{-6}[\mathrm{~m}]$.

Experiments with SS316L powder layer of 40 and $80 \mu \mathrm{m}$ thickness were realized with laser power of $30 \mathrm{~W}$ and power and scanning speed of 50 to $300 \mathrm{~mm} . \mathrm{s}^{-1}$. In both case we use the same true temperature restoration method described above. There were the same process parameters in the experiments with SS410 powder but only with $40 \mu \mathrm{m}$ of powder layer. Since the powder-free space on the track plane was significant compared to the SS316L powder experiments and the on-line image analysis showed the track width in-process fluctuation, the small-sized analysis was carried out with variation of above described true temperature restoration method. 

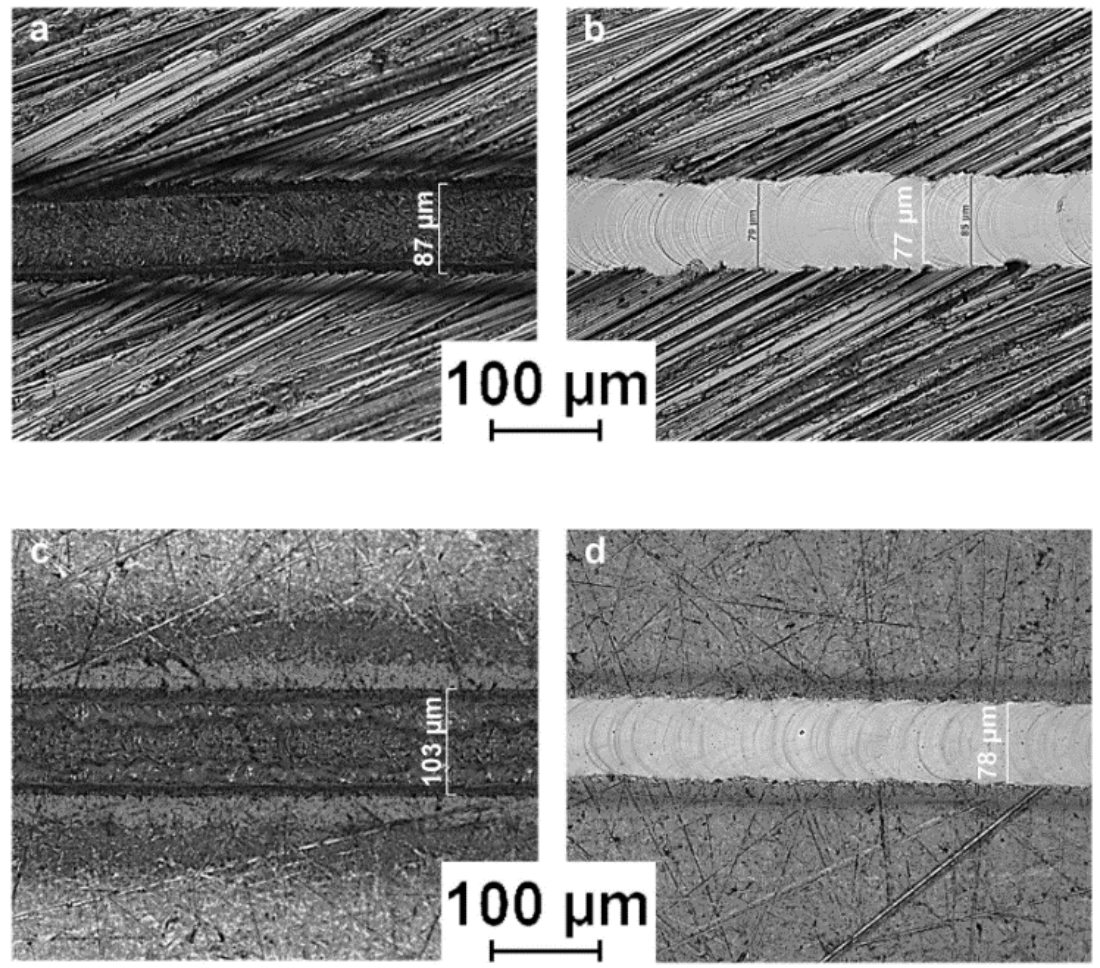

Fig. 2. Top view of the laser passes on the solid substrates of SS304L: (a) and (b) with $R a 10 \mu \mathrm{m}$, (c) and d) with $R a 3 \mu \mathrm{m}$, (a) and (c) experiments in air, (b) and (d) experiments in argon. Process parameters: laser power is $30 \mathrm{~W}$, scanning speed is $100 \mathrm{~mm} \cdot \mathrm{s}^{-1}$.

Figure 4 presents explanation of the terms track and powder-free space.

\section{Results and discussion}

\subsection{Solid material laser treatment optical diagnostics}

Figure 2 presents the example of single laser passes in air (Figs. 2a and 2c) and in argon protective atmosphere (Figs. 2b and 2d). The black color on the surface (Figs. 2a and 2c) states strong oxidation. The less rough samples present less intensive color (and thus less oxidation) apparently due to the less laser energy absorbed by more reflective surface. At the laser pass side one could identify HAZ (heat affected zone) with different from remelted zone color that could be attributed to the sub melting point temperatures. The samples prepared in argon present no oxidation evidence and sharp boundary between remelted zone, HAZ and bulk material. Only substrate with $R a 10 \mu \mathrm{m}$ prepared in argon did not reveal HAZ that was attributed to the intrinsic properties of the image capture. All the samples prepared without protective atmosphere showed greater HAZ compared to the ones prepared in argon.

The surface roughness did not influence the track width during laser treatment in argon. This phenomenon is due to the less of overall energy in the working zone. It is clear that with oxidation some heat adds in the melt pool by exothermic reaction, by increase of absorptivity of oxides and due to the higher temperatures (that is true for metals).

In Figure 3, the digital level and true temperatures are presented. The Table 4 presents mean value of digital level for the all experiments that was calculated with respect to the melt pool size. The standard deviation became not more $10 \%$ that is accessible precision. It should be noted, that for the samples with $R a 10 \mu \mathrm{m}$ roughness measurements there was an error in the center of laser spot due to the plume that significantly changes the emissivity coefficient for the more than $1750{ }^{\circ} \mathrm{C}$ of true temperature.

One could see that the peak temperature of the melt pool for the samples with $R a 10 \mu \mathrm{m}$ is greater than for the $R a 3 \mu \mathrm{m}$ one (about additional $100{ }^{\circ} \mathrm{C}$ ). Considering pairwise Figures $3 \mathrm{a}$ and $3 \mathrm{c}$ and $3 \mathrm{~b}$ and $3 \mathrm{~d}$ one could note that the oxidation effect results in additional 50 to $200{ }^{\circ} \mathrm{C}$ to the peak temperatures. More interesting are the difference in temperature profiles shapes of $R a 10 \mu \mathrm{m}$ and $R a 3 \mu \mathrm{m}$ rough sample shapes. It is clear, that on the sample with $R a 3 \mu \mathrm{m}$ above the melting point the shape converging and the resulting temperatures inside the melt pool greatly differs from the same for $R a 10 \mu \mathrm{m}$ samples. This phenomenon becomes clearer if we take into account that with temperature raising the absorptivity of laser radiance increases. Considering Gaussian transversal energy distribution, it shows that the temperatures became to the melting point and above there where the laser radiance intensity was sufficient. This resulting in isotherm size reduction: for example, on the temperature 
a

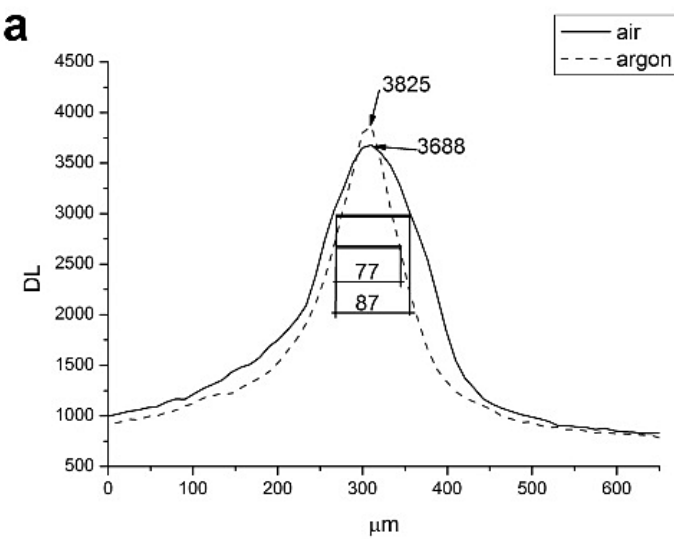

C

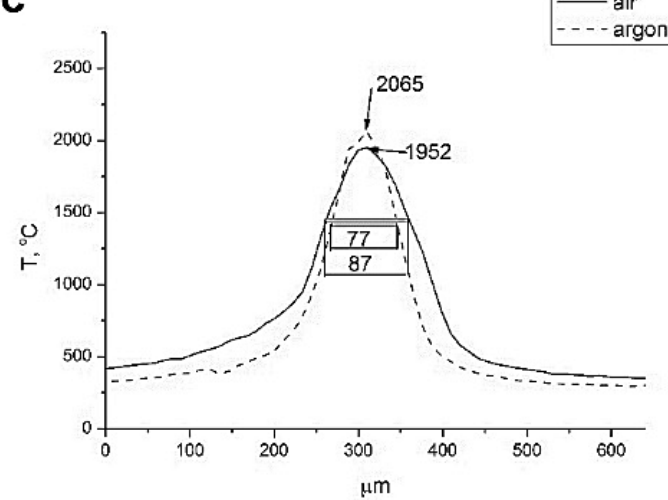

b

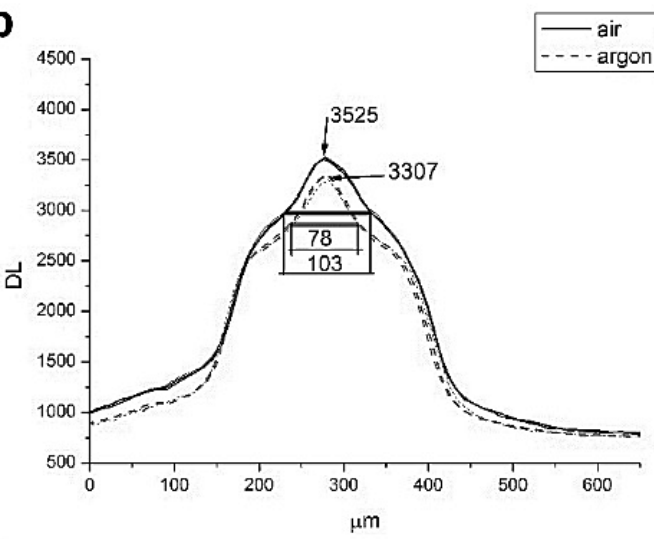

d

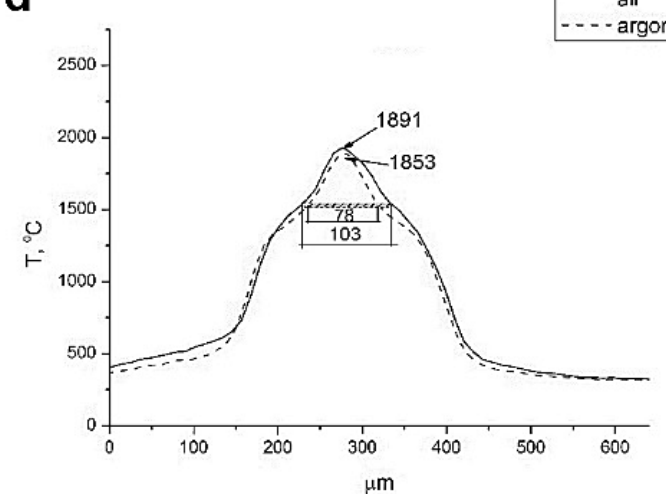

Fig. 3. Optical diagnostic results (transversal temperature profile) corresponding to the experiments from Figure 2: digital level for substrate with $R a 10 \mu \mathrm{m}$ (a) for substrate with $R a 3 \mu \mathrm{m}$ (b); true temperature for substrate with $R a 10 \mu \mathrm{m}$ (c), for substrate with $R a 3 \mu \mathrm{m}$ (d). DL - digital level.

$1750{ }^{\circ} \mathrm{C}$ the melt pool size was $53 \mu \mathrm{m}$ for $R a 10 \mu \mathrm{m}$ sample (Fig. 3c) and $39 \mu \mathrm{m}$ for $R a 3 \mu \mathrm{m}$ sample (Fig. 3d).

\subsection{SS $316 \mathrm{~L}$ powder SLM optical diagnostics (powder layer thickness of $40 \mu \mathrm{m}$ )}

All the single-tracks produced without protective atmosphere showed blurred surface while the singletracks produced in argon showed metallic luster. The air-produced tracks widths were a little larger than argon-produced ones. The temperature transversal profiles shapes for both air and argon-produced tracks were almost the same. Compared to the experiments with solid material it could be reasoned that the material state significantly changes the thermal conductivity and absorption conditions. The changing of thermal conductivity could be estimate as $10 \%$ of solid material thermal conductivity for $55 \%$ of powder layer porosity [13] but only on the first stage of heating. This effect allows heat accumulating. After the time of full thickness layer melting the liquid connects to the solid surface and the conductivity rising up.

Figure 5 presents digital level for the samples from Figure 4 (Figs. 5a and 5b) and a set of restored true temperatures for the different scanning speeds. It was shown that the true temperatures for all samples produced in air was higher for about $500{ }^{\circ} \mathrm{C}$ than for the argon-produced samples. Evidently, the exothermic reaction adds energy and was responsible for this temperature raising. One could note a little shape distortion for the argon-produced sample at the $4500 \mathrm{DL}$ (about $2000{ }^{\circ} \mathrm{C}$ ) same as for the solid surface treatment Figures $3 \mathrm{~b}$ and $3 \mathrm{~d}$. The more interesting was steadiness of the peak temperature with different scanning speed for the samples produced in argon. This could be an approval for the laser power as the most significant process parameter in SLM technology [14]. With increasing of energy density the radiation transfer becomes dominating heat dissipating mechanism so this is the evident reason for the temperature upper limit (Fig. 5d, 50, 100, 200 mm.s ${ }^{-1}$ ).

Only sample with $300 \mathrm{~mm} . \mathrm{s}^{-1}$ (Fig. 5d) scanning speed presents temperature decrease. The possible reason could be achieved if consider the track-substrate bonding. While the process parameters provide the optimal regime for track bonding with the substrate, the part of the energy goes into the bulk. The liquid material flows inside the melt pool arrange the temperature and the temperature profile goes wider. Since the scanning speed become insufficient to make a metallurgical contact between the track and substrate, the effect calling balling occurs when the liquid material breaks off and forms stand-alone balls. 


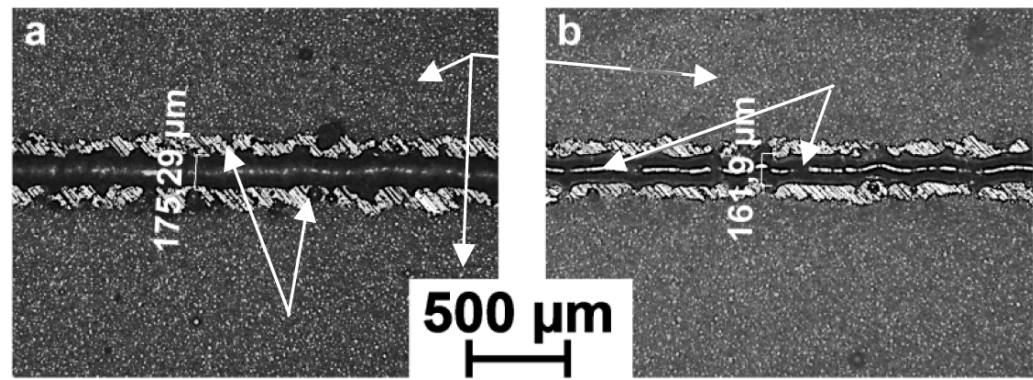

Fig. 4. Top view of the single-tracks of SS316L powder: produced in air (a), and in argon (b). Process parameters: laser power is $30 \mathrm{~W}$, scanning speed is $100 \mathrm{~mm} \cdot \mathrm{s}^{-1}$, powder layer is $40 \mu \mathrm{m}$.

a
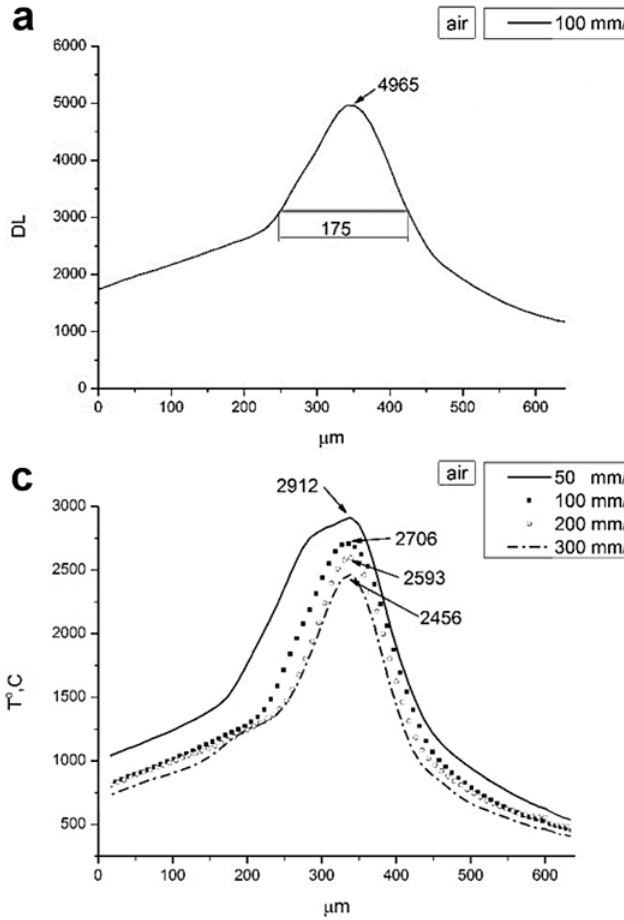

b

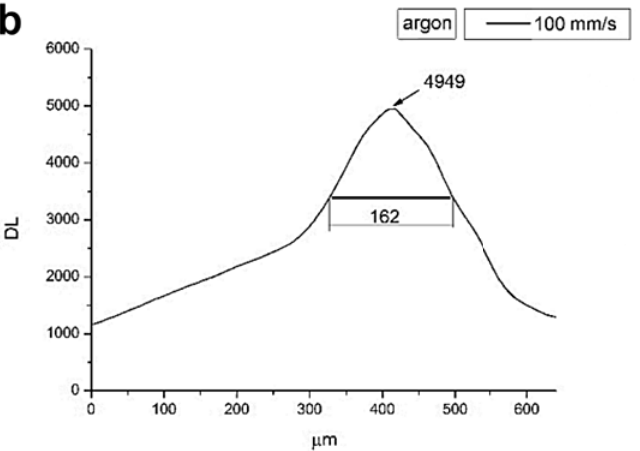

d

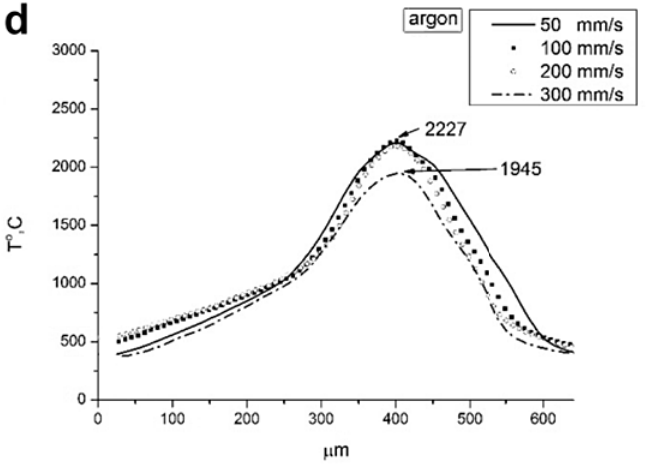

Fig. 5. Optical diagnostic results (transversal temperature profile) corresponding to the experiments from Figure 4: brightness temperature for single-tracks produced in air (a), and in argon (b); true temperature of single-tracks produced in air (c), and in argon (d) laser power is 30W; scanning speeds are 50, 100, 200 and $300 \mathrm{~mm} . \mathrm{s}^{-1}$, SS316L powder layer is $40 \mu \mathrm{m}$.

As on the scanning speed of $300 \mathrm{~mm} \cdot \mathrm{s}^{-1}$ the balls were occurring the absorbing laser energy reduces. This effect was not detected on the samples prepared in air because of additional heating up by exothermic reaction that allows tracks to have a good bonding with substrate with uniform track geometry. This effect could be easily introduced in the automatic optical control system for SLM machines.

With the same parameters the powder material heating up to the greater temperature that the solid surface. It is connected to the significant difference in absorptivity of solid surface and powder layer. The problem was discussed in Reference [15] where it was concluded that the powder layer absorptivity could be considered as pseudovolumetric higher that surface one.

\subsection{SS 316L powder SLM optical diagnostics (powder layer thickness of $80 \mu \mathrm{m}$ )}

The experiments with thick powder layer showed that with $30 \mathrm{~W}$ of laser power and scanning speed of $200 \mathrm{~mm} . \mathrm{s}^{-1}$ the balling effect occurs and there was no successful bonding between track and substrate. The scanning speed of $100 \mathrm{~mm} \cdot \mathrm{s}^{-1}$ provides connection with the substrate but the tracks was not stable in longitudinal direction that is evidently showed at the Figure 6 . The scanning speed of $50 \mathrm{~mm} . \mathrm{s}^{-1}$ provide uniform track geometry for the samples prepared in air but not stable in argon. It became clear that scanning speed of $100 \mathrm{~mm} . \mathrm{s}^{-1}$ is the borderline value between optimal and nonoptimal regimes for both air and argon prepared samples. 
Table 4. Mean value of melting point signal level given for all experiments.

\begin{tabular}{ccccc}
\hline & $R a 10 \mu \mathrm{m}$ in air & $R a 10 \mu \mathrm{m}$ in argon & $R a 3 \mu \mathrm{m}$ in air & $R a 3 \mu \mathrm{m}$ in argon \\
\hline Mean value, DL & 2988.50 & 2619.5 & 2885.50 & 2797.58 \\
Std. dev., DL & 123.90 & 101.97 & 235.69 & 146.32 \\
Std. dev., \% & 4.15 & 3.89 & 8.17 & 5.23 \\
Calculated emissivity coefficient & 0.40 & 0.32 & 0.41 & 0.38 \\
\hline
\end{tabular}

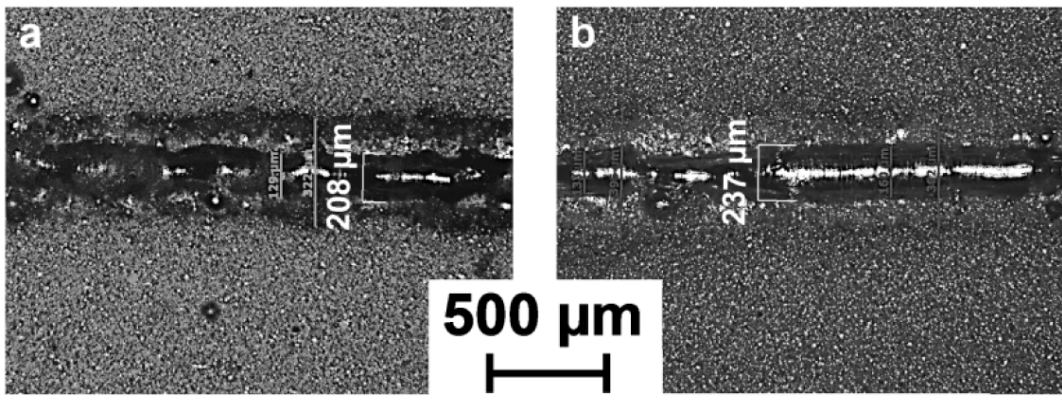

Fig. 6. Top view of the single-tracks of SS316L powder: produced in air (a), and in argon (b). Process parameters: laser power is $30 \mathrm{~W}$, scanning speed is $100 \mathrm{~mm} \cdot \mathrm{s}^{-1}$, powder layer is $80 \mu \mathrm{m}$.

One could see on the Figures $7 \mathrm{c}$ and $7 \mathrm{~d}$ that the true temperature for both prepared in air and in argon samples are almost the same but fluctuate inside the group that could be connected to the deviation in track-substrate bonding. Apparently, the reason was the track width growing (Tab. 7) compared to the $40 \mu \mathrm{m}$ of powder layer samples (Fig. 5). This is the case similar to the case of $300 \mathrm{~mm} . \mathrm{s}^{-1}$ scanning speed on the $40 \mu \mathrm{m}$ of powder layer samples (Fig. 5c) where the deviation of track-substrate bonding decreases the peak temperature. In Reference [1] it was shown that with rising of convection heat exchange the temperature gradient inside the melt pool goes down. If we take into account the track width growing connecting with capture of more powder material inside the melt pool, it became clear that the convection plays significant role in this temperature reduction case. We also have to take into consideration the true temperature restoration method error.

It should be highlighted that in the case of thick powder layer the thermal properties of the track-substrate system were changed compared to the case with thin powder layer. As it was stated above the thermal conductivity of porous powder differs from the solid material. In this view, the thickness of powder influences the thermal properties of the whole system. Since there is no good connection/bonding with the substrate with relative high conductivity, the heat goes laterally at the same intensity as in the substrate direction. This explanation of track width growing is approved by the experiments in air where the additional heat of exothermic reaction allows good tracksubstrate bonding resulting in narrower track and lower temperature.

The last significant result of this experiment was the unchanged emissivity coefficient compared to the experiments with thin powder layer of $40 \mu \mathrm{m}$ that could be useful in the automatic and semiautomatic optical control system.

\subsection{SS 410 powder SLM optical diagnostics}

During the experiments with the high-speed CCD camera it was shown that the melt pool width has inprocess changes $[6,9,16]$. The melt pool is wider during the process than the resulting solid track and narrowing at solidification stage that is calling constriction. The powder free zone is exactly not the result of this process since the adjacent to melt pool powder particles were involved into this. The in-process melt pool is definitely (by high speed camera capture) narrower than the powder free zone. At the previous experiment the track width at the maximum value was taken in the consideration but in fact it is a little more than the exactly track width that was taken into account in calculations. Since the emissivity coefficient needs to be calculated at the melting point, there is uncertainty in precise identification of melt pool size. The sizes of the powder-free space, exactly track and the mean value dimensions were taken in the calculation (Fig. 8).

The resulting measurements and calculations were presented in Figure 9. It is shown, that the true temperatures calculated by substituting track width and powderfree space has about 1000 to $1400^{\circ} \mathrm{C}$ difference (for argon and air produced samples).

The average calculation gives about similar the true temperatures for air and argon produced samples and the question of precise measurement of melt pool width remains open. By this accuracy of true temperature restoration, it is enough to make estimative evaluation of melt pool width but the better solution is to apply the optical diagnostic means in visible wavelength range i.e. highspeed CCD camera equipped with filters cutting away 

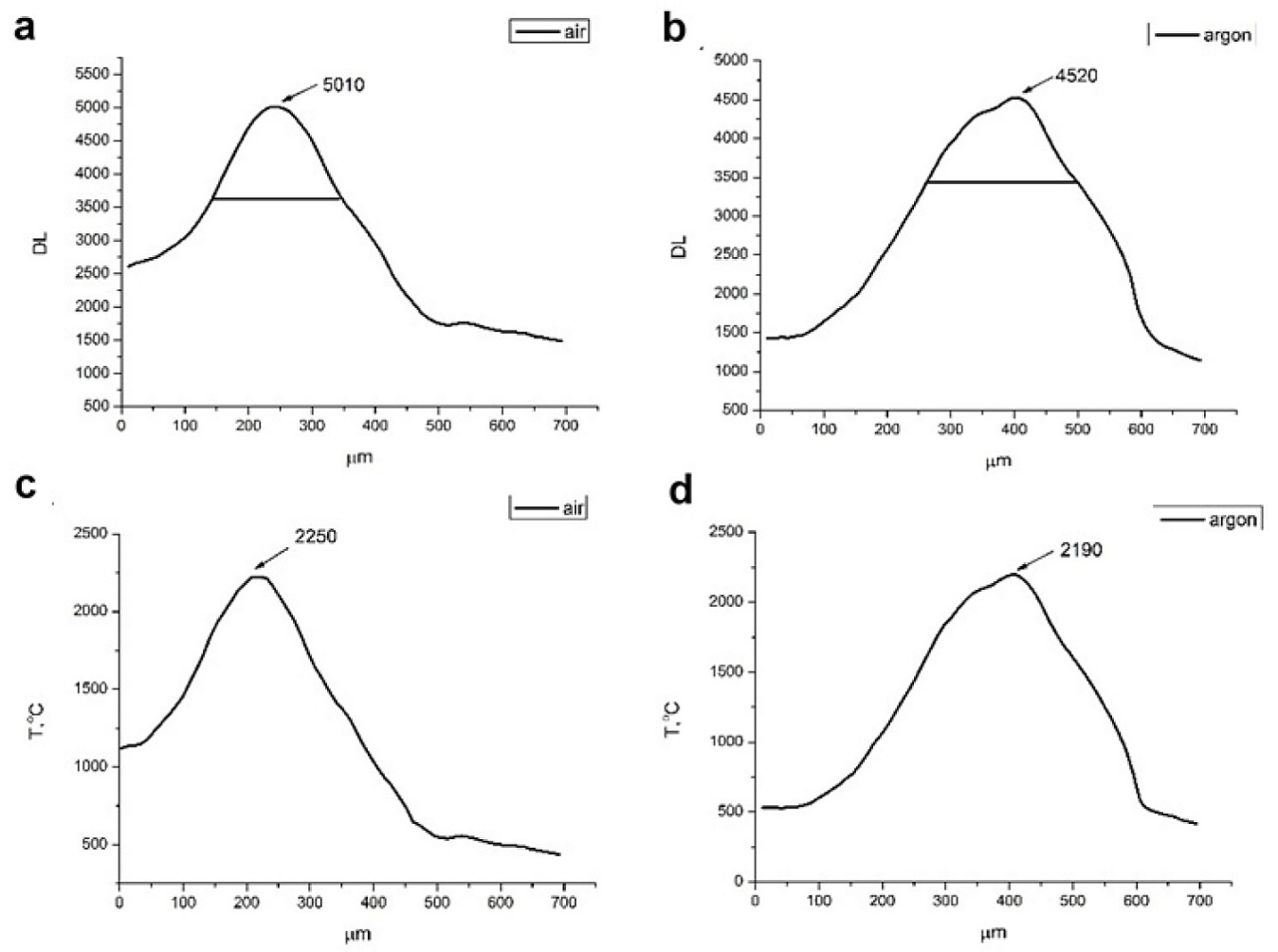

Fig. 7. Optical diagnostic results (transversal temperature profile) corresponding to the experiments from Figure 6: digital level for single-tracks produced in air (a), and in argon (b); true temperature of single-tracks produced in air (c), and in argon (d). Horizontal lines mark the melt pool width (see Tab. 7). Process parameters: laser power is $30 \mathrm{~W}$, scanning speed is $100 \mathrm{~mm} . \mathrm{s}^{-1}$, powder layer is $80 \mu \mathrm{m}$.

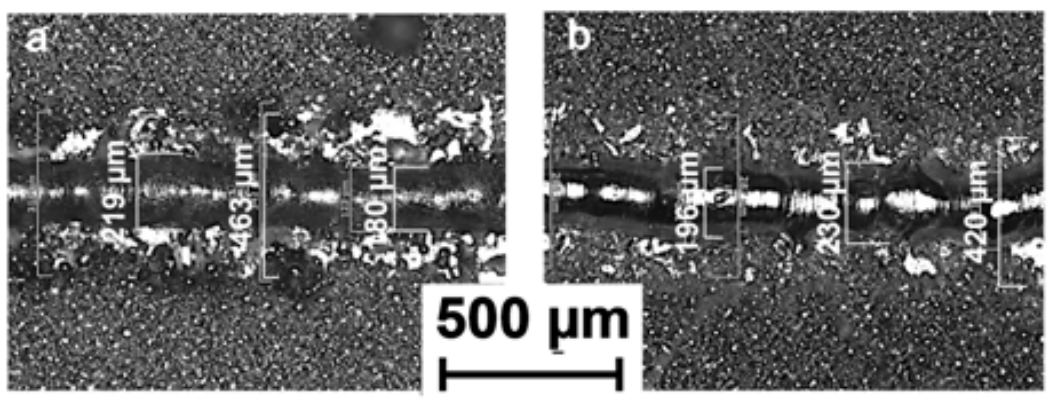

Fig. 8. Top view of the single-tracks of SS410 powder: produced in air (a), and in argon (b). Process parameters: laser power is $30 \mathrm{~W}$, scanning speed is $100 \mathrm{~mm} \cdot \mathrm{s}^{-1}$, powder layer is $40 \mu \mathrm{m}$.

the laser and near laser radiation, notch filters with laser illumination etc.

The calculated peak true temperatures of air and argon-prepared samples are almost the same (about $2500{ }^{\circ} \mathrm{C}$ ). One could see in Figure 8 that the sample prepared in air has uniform track geometry while the sample prepared in argon has some geometrical deviations. As the argon-prepared sample had lower metallurgical bonding with the substrate, the heat was accumulated in the melt pool and the temperature became the same as for the air prepared sample where the oxidation exothermic reaction involves additional heat. This additional heat allows good track-substrate bonding which sharply increases the heat dissipating in substrate and temperature decreasing. Exactly track width of both air and argon-prepared samples are greater than for the SS316L and solid samples. It could be assigned to the higher thermal conductivity. The greater thermal conductivity the greater scanning speed is needed to preserve track width close to the laser spot diameter that is known for high-conductive alloys such as aluminum [17].

The other possible hypothesis is the low emissivity coefficient (Tab. 8) compared to the SS316L experiments (Tabs. 5 and 6 ). Since the radiation heat transfer de- 

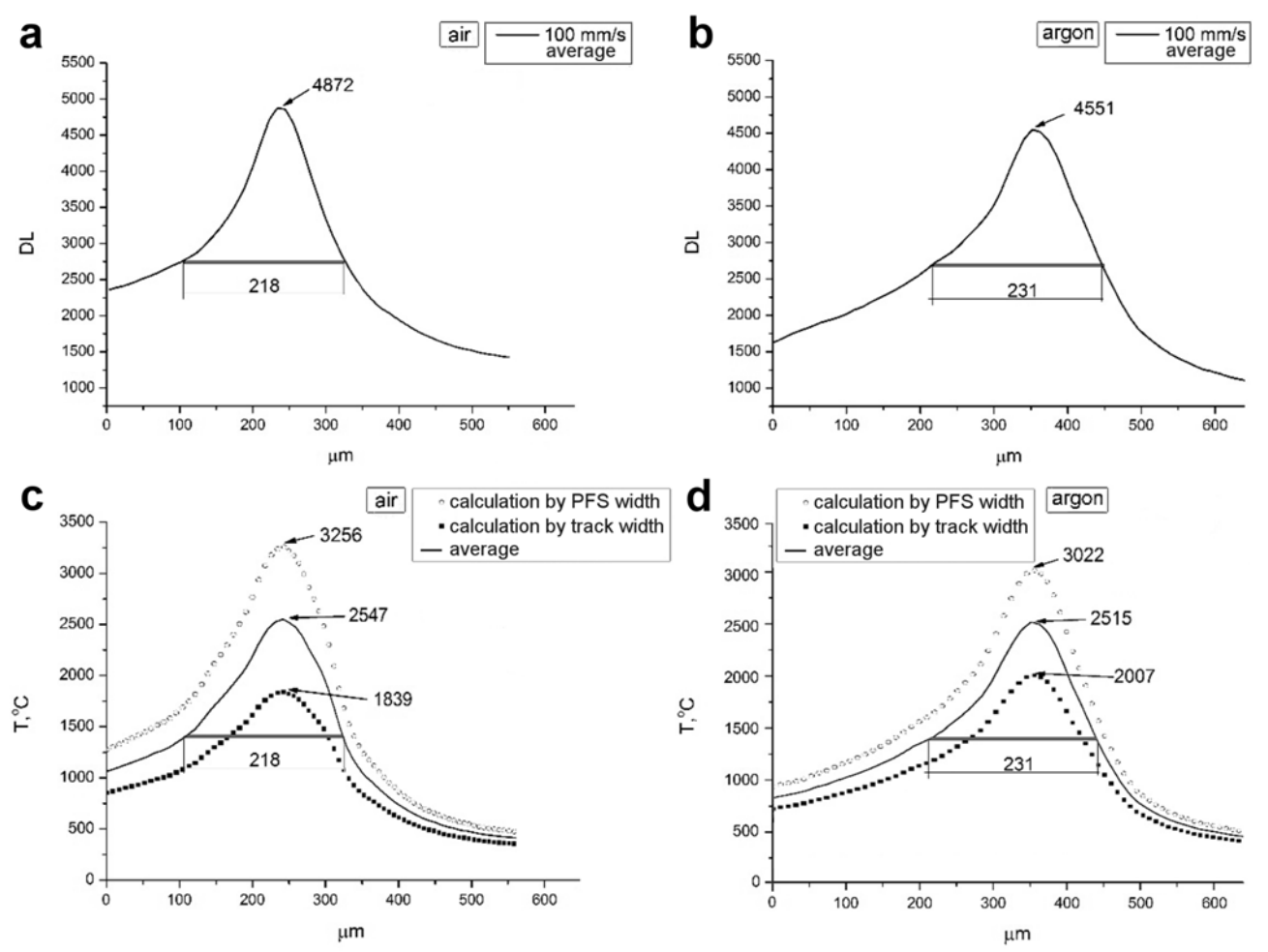

Fig. 9. Optical diagnostic results (transversal temperature profile) corresponding to the experiments from Figure 8: digital level for single-tracks produced in air (a), and in argon (b); true temperature of single-tracks produced in air (c), and in argon d). PFS - powder-free space.

Table 5. Mean value of melting point signal level given for all experiments.

\begin{tabular}{ccc}
\hline & SS316L powder $40 \mu$ m layer in air & SS316L powder $40 \mu$ m layer in argon \\
\hline Mean value, DL & 3054.82 & 3360.11 \\
Std. dev., DL & 96.37 & 122.39 \\
Std. dev., $\%$ & 3.15 & 3.64 \\
Calculated emissivity coefficient & 0.6 & 0.5 \\
\hline
\end{tabular}

Table 6. Mean value of melting point signal level given for all experiments.

\begin{tabular}{ccc}
\hline & SS316L powder $80 \mu$ m layer in air & SS316L powder $80 \mu$ m layer in argon \\
\hline Mean value, DL & 3495,33 & 3123,67 \\
Std. dev., DL & 150,6249 & 371,2566 \\
Std. dev., \% & 4,309315 & 11,88528 \\
Calculated emissivity coefficient & 0.64 & 0.51 \\
\hline
\end{tabular}

Table 7. The width of the track for the experiments from Figures $7 \mathrm{a}$ and $7 \mathrm{~b}$.

\begin{tabular}{ccc}
\hline No. of experiment & SS316L powder 80 $\mu$ m layer in air & SS316L powder $80 \mu \mathrm{m}$ layer in argon \\
\hline 1 & 205 & 236 \\
2 & 211 & 241 \\
3 & 207 & 231 \\
\hline
\end{tabular}


M. Doubenskaia et al.: Mechanics \& Industry 17, 707 (2016)

Table 8. Mean value of melting point signal level given for all experiments.

\begin{tabular}{ccc}
\hline & SS410 powder $40 \mu$ m layer in air & SS410 powder 40 $\mu$ m layer in argon \\
\hline Mean value, DL & 2779,83 & 2673,83 \\
Std. dev., DL & 34,44077 & 180,5297 \\
Std. dev., \% & 1,238951 & 6,751718 \\
Calculated emissivity coefficient & 0.35 & 0.31 \\
(mean value of melt pool width) & & \\
\hline
\end{tabular}

pends on the material emissivity properties it means that the radiation heat transfer was not significant in the case of SS410 experiments that probably allows accumulating heat.

The difference in laser power absorption coefficient should be considered in future works as a influenced factor since the SS316 and SS410 have different element composition.

Returned to the powder-free space size, it could be concluded that it was greater for the SS410 samples (about $450 \mu \mathrm{m}$ in air and $420 \mu \mathrm{m}$ in argon) than for the SS316 samples (about $170 \mu \mathrm{m}$ in air and $150 \mu \mathrm{m}$ in argon at $40 \mu \mathrm{m}$ powder layer; about $220 \mu \mathrm{m}$ in air and $200 \mu \mathrm{m}$ in argon at $80 \mu \mathrm{m}$ powder layer) for the same process parameters. Considering the optical diagnostic results for all the experiments it became clear that the greater melt pool lifetime the greater powder-free zone as the greater amount of side adjacent powder involves in the melt pool and pushed away. There is no exact theory describing powder involving mechanism so it is impossible to precise reasoning the effect.

The results showed that not only thermal conductivity significantly influences the quality of resulted material but also the emissivity, absorption coefficient and the process parameters. It also states that there is a strong need to make an optimization of process parameters particularly for each material even it is one-class materials as steels.

\section{Conclusion}

Temperature monitoring of SLM process in the protective atmosphere using IR-camera allows collecting additional data about the process. The experiments clearly show the influence of the process parameters (surface finishing, scanning speed, thermal properties) on the input signal also in digital level that could be translated in single-track quality as it was possible by pyrometer and high-speed CCD camera in Reference [6]. The applying of the high-speed CCD visible range camera in pair with IR-camera allows making graphical clearly arranged engineer/user-friendly presented results by online calculating of true temperatures, catching track and powder-free space width etc. It was shown, that for argon processing with powder layer thickness increasing the temperature increases slowly as well as the scanning speed did not influence on the melt pool surface temperature if good bonding with substrate was established.

The considered scanning speed of $100 \mathrm{~mm} . \mathrm{s}^{-1}$ was as the borderline for the argon-produced samples because of lack of energy to produce good metallurgical bonding in some cases. On the other hand, the excess of heat produced by exothermic oxidation reaction provide better bonding track-substrate. The additional temperature could be considered as 50 to $500{ }^{\circ} \mathrm{C}$ influenced by the process conditions. The oxide content should be evaluated in the future works but the surface of the air-produced samples was blurred and black of the oxides. The other problem with the melting in air remains the difficulty to capture the adequate signal because of plume.

In contrast, tracks produced in argon showed no oxides (by metallic luster of samples). To provide the same geometry as for the samples produced in air it was sufficient to add some laser power.

The calculated emissivity coefficient was always less for the argon-produced samples than for the air-produced ones. For the SS316L powder the emissivity did not influenced by powder thickness. Apparently, the emissivity depends on the surface roughness but it needs to deeply evaluating in future. As a conclusion, it could be stated that the emissivity is the intrinsic property of material and it should be evaluated to each material with regard to surface state.

Acknowledgements. This work has been financed by the sources of Russian Science Foundation (grant agreement No. 14-19-01647 from 04.07.2014).

\section{References}

[1] I. Smurov, M. Doubenskaia, Temperature monitoring by optical methods in laser processing, Laser-Assisted Fabrication of Materials (2013) 375-422

[2] T. Craeghs, S. Clijster, E. Yasa, F. Bechmann, S. Berumen, J.P. Kruth, Determination of geometrical factors in layerwise laser melting using optical process monitoring, Opt. Lasers En. 49 (2011) 1440-1446

[3] U. Thombansen, A. Gatej, M. Pereira, Tracking the course of the manufacturing process in selective laser melting, Proc. SPIE, Int. Soc. Opt. Photonics (2014) 8963

[4] Y. Chivel, I. Smurov, On-line temperature monitoring in selective laser sintering/melting, Phys. Procedia 5 (2010) $515-521$

[5] H. Krauss, C.M.F. Eschey Zaeh, Thermography for monitoring the selective laser melting process, Proc. of the 23rd Annual International Solid Freeform Fabrication Symposium, The University of Texas at Austin, Austin, TX (2012) 999-1014

[6] M. Doubenskaia, S. Grigoriev, I. Zhirnov, I. Smurov, Parametric analysis of SLM using comprehensive optical monitoring, Rapid Prototyping J. 22 (2016) 40-50 
[7] S. Elhadj, M.J. Matthews, S.T. Yang, Combined infrared thermal imaging and laser heating for the study of materials thermophysical and processing properties at high temperatures, Crit. Rev. Solid State Mater. Sci. 39 (2014) 175-196

[8] M.J. Matthews, S. Rubenchik, G. Guss, Characterization of melt-flow dynamics in selective laser melting (SLM) processes, CLEO: Applications and Technology (pp. ATh3A-Optical Society of America (2015) 1-2

[9] I.V. Zhirnov, I. Smurov, M.A. Yu., Doubenskaia Optical monitoring of selective laser melting: influence of scanning speed and laser power on the melt pool geometry on the surface of INOX 316L powder layer (In Russian), Vestnik MGTU Stankin 3 (2015) 52-56

[10] J.P. Kruth, P. Mercelis, J. Van Vaerenbergh, T. Craeghs, Feedback control of selective laser melting, Proceedings of the 3rd international conference on advanced research in virtual and rapid prototyping (2007) 521-527

[11] A. Okunkova, M. Volosova, P. Peretyagin, I. Zhirnov, P. Podrabinnik, S.V. Fedorov, A. Gusarov, Study of laser beam modulation influence on structure of materials produced by additive manufacturing, Adv. Mater. Lett. 7 (2016) 111-115
[12] C.Y. Ho, T.K. Chu, Electrical resistivity and thermal conductivity of nine selected AISI stainless steels, Cindas report 45, CINDAS/TEPIAC Publication (1977) 51

[13] R.M. German, K.F. Hens, J.L. Johnson, Powder metallurgy processing of thermal management materials for microelectronic applications, Int. J. Powder Metall. 30 (1994) 205-215

[14] I. Yadroitsev, I. Yadroitsava, P. Bertrand, I. Smurov, Factor analysis of selective laser melting process parameters and geometrical characteristics of synthesized single tracks, Rapid Prototyping Journal 18 (2012) 201-208

[15] A.V. Gusarov, I. Smurov, Radiation transfer in metallic powder beds used in laser processing, J. Quantitative Spectroscopy Radiative Transf. 111 (2010) 2517-2527

[16] I.V. Zhirnov, P.A. Podrabinnik, M. Tokbergenov, A.A. Okunkova, I.Y. Smurov, Optical Monitoring and Diagnostics of SLM Processing for Single Track Formation from Co-Cr Alloy, Materials Science Forum 834 (2015) 51-60

[17] S.N. Grigoriev, T.V. Tarasova, G.O. Gvozdeva, S. Nowotny, Structure formation of hypereutectic Al-Sialloys produced by laser surface treatment, Strojniški vestnik-J. Mech. Eng. 60 (2014) 389-394 